\title{
Leiomyosarcoma of the spermatic cord
}

\author{
A. R. DE BOLLA* \\ F.R.C.S.
}

D. G. ARKELL

M.Sc., F.R.C.S.

Department of Urology, Dudley Road, Hospital, Birmingham B18 7QH

\begin{abstract}
Summary
Leiomyosarcoma of the spermatic cord is extremely rare. We report a case associated with recurrent papillary bladder tumours and benign hyperplasia of the prostate. The use of adjuvant chemotherapy is described for the first time in the management of this condition.
\end{abstract}

KEY WORDS: leiomyosarcoma, spermatic cord, chemotherapy.

\section{Introduction}

Neoplasms affecting the spermatic cord are rare (Zuckner and Aronberg, 1951; Bissada, Finkbeiner and Redman, 1976) and 70\% show benign characteristics. The most commonly reported malignant tumour is the rhabdomyosarcoma, fibrosarcomas and leiomyosarcomas occurring less often. We believe there have been 32 cases of leiomyosarcoma of the spermatic cord reported since its first description by Patel in 1907.

\section{Case report}

A 63-year-old man presented in 1975 with painless haematuria. This was found to be due to a superficial papillary bladder tumour near the left ureteric orifice and was treated by cystodiathermy. Regular followup cystoscopies revealed recurrent bladder tumours in March 1979 and these were similarly treated.

In August 1979, he complained of a firm, painless mobile mass in the left inguinal region, which had been present for 6 weeks and was slowly enlarging. At operation, a $3 \times 3 \mathrm{~cm}$ size cystic mass was found within the spermatic cord, $3 \mathrm{~cm}$ distal to the deep inguinal ring. Biopsy and frozen section examination demonstrated a spindle-celled sarcoma and left radical orchidectomy was performed. Subsequent histological examination showed a markedly vascular tumour with areas of haemorrhage and the features of a leiomyosarcoma. The tumour was composed of

\footnotetext{
*Present address: The Queen Elizabeth Hospital, Queen Elizabeth Medical Centre, Edgbaston, Birmingham B15 2TH.
}

spindle cells with large binucleate and multinucleate cells scattered within and cleft-like spaces with flattened endothelial cell lining (Fig. 1).

Routine haematology and biochemistry tests were normal. Chest X-ray, isotope liver and bone scansi showed no metastases and an intravenous urograme revealed only a trabeculated bladder and a bladdere diverticulum.

Three weeks postoperatively, a course of adjuvan chemotherapy was commenced. Vincristine, $2 \mathrm{mgg}$ was given intravenously, followed $6 \mathrm{hr}$ later by adriamycin, $50 \mathrm{mg}$, and methotrexate, $100 \mathrm{mg} \Leftarrow$ Leucovorin, $27 \mathrm{mg}$, was given intramuscularly afte $24 \mathrm{hr}$. Treatment was continued as an in-patient at monthly intervals for one year, 2-monthly intervê for 6 months, and then on 2 further occasions, eact 3 months apart. The treatment was well tolerated, theres being no evidence of recurrence or dissemination.o the tumour 32 months postoperatively. Severe prosta tic symptoms developed 12 months postoperatively and a transurethral resection was performed, histo 0 logy demonstrating benign hyperplasia with no evidence of malignancy. No further recurrence of the bladder tumours has occurred.

\section{Discussion}

Since the first reported case of leiomyosarcoma of the spermatic cord, further cases have been described (Jenkins and Subbuswamy, 1972; Deluise, Drapez and Gray, 1976; Banik and Guha, 1979; Buckley ando Tolley, 1981). Kyle (1966) reviewed the subject some years ago. These tumours usually occur in men ove the age of 50 years, but details available from $32 \pi$ previously reported cases show a wide range of age ap presentation (15-78 years). They are more ofter [ situated near the testis than in the inguinal region. II is probable that the association of the tumour witho prostatic hyperplasia (Zuckner and Aronberg, 195 ti Bevan, 1954) is accounted for by age alone, but we्ष have found no previous reference to associate bladder tumours.

There has been debate as to the origin of this 


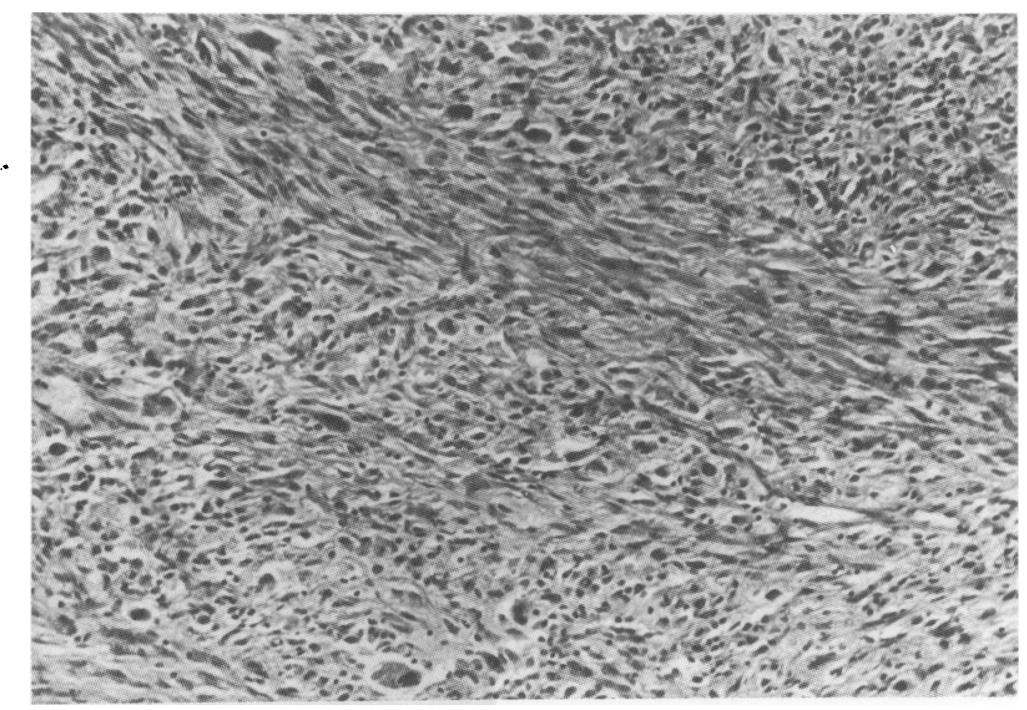

FiG. 1. Section of tumour $(\times 75)$.

tumour. It has been suggested that it derives from the walls of blood vessels, the vas deferens, smooth muscle cells of the cremaster and undifferentiated mesenchymal cells. Some reports have pointed to the development of sarcomatous change within a benign leiomyoma (Jenkins and Subbuswamy, 1972; Bevan, 1954). Macroscopically, the tumours appear encapsulated, firm and nodular with cystic and necrotic areas (Jenkins and Subbuswamy, 1972; Buckley and Tolley, 1981; Kyle, 1966). Microscopically, they consist of interlacing strands of spindle shaped cells with marked variation in nuclear size and chromatic distribution, and large numbers of mitotic figures.

The spread of leiomyosarcoma of the spermatic cord is believed to be primarily by the haematogenous route (Banik and Guha, 1979; Strong, 1942). Due to their rarity, full evaluation of different forms of therapy is lacking, but the cornerstone of treatment is radical orchidectomy with ligation of the spermatic cord at the deep inguinal ring. The role of surgery and radiotherapy to the retroperitoneal lymph nodes is undecided, though some authors (Banik and Guha, 1979; Weitzner, 1973) feel it to be unwarranted.

As with many other soft tissue sarcomas, the prognosis for patients with leiomyosarcoma of the spermatic cord is poor. Kyle (1966) suggested a probable 5 year survival rate of $10-15 \%$. Of the 22 cases in his series, nearly half died in less than 2 years. We were able to find only one case report in which specific antimitotic chemotherapy was given for the treatment of lung metastases from this tumour (Jenkins and Subbuswamy, 1972). We are unaware of adjuvant chemotherapy previously being used in this condition in the absence of detectable metastases. In view of the poor outlook for patients with this tumour, a well tolerated course of chemotherapy, such as was given in this case, would seem to be well justified.

\section{Acknowledgments}

We wish to thank Dr W. Shortland-Webb for his help with the histological reports, and Miss G. Fradgley for typing the manuscripts.

\section{References}

BANIK, S. \& GUHA, P.K. (1979) Paratesticular rhabdomyosarcomas and leiomyosarcomas: A clinicopathological review. Journal of Urology, 121, 823.

BevaN, P.G. (1954) Malignant leiomyoma of the spermatic cord. British Journal of Surgery, 42, 101.

Bissada, N.K., Finkbeiner, A.E. \& Redman, J.F. (1976) Paratesticular sarcomas: Review of management. Journal of Urology, 116, 198.

BUCKLEY, P.M. \& TOLLEY, D.A. (1981) Leimyosarcoma of the spermatic cord. British Journal of Urology, 53, 193.

DELUISE, V.P., DRAPER, J.W. \& GRAY, G.F. (1976) Smooth muscle tumours of the testicular adnexa. Journal of Urology, 115, 685.

JENKINS, D.G. \& SUbBUSWAMY, S.G. (1972) Leiomyosarcoma of the spermatic cord. British Journal of Surgery, 59, 408.

KYLE, V.N. (1966) Leiomyosarcoma of the spermatic cord: a review of the literature and report of an additional case. Journal of Urology, 96, 795.

PATEL, A. (1907) Tumeur maligne du cordon spermatique (leiomyome malin). Lyon médical, 104, 12.

STRONG, G.H. (1942) Lipoma of the spermatic cord: case report and review of the literature. Journal of Urology, 48, 527.

WEITZNER, S. (1973) Leiomyosarcoma of the spermatic cord and retroperitoneal lymph node dissection. American Surgeon, 39, 352.

ZUCKNER, J. \& ARONBERG, L.M. (1951) Leiomyosarcoma of the spermatic cord with the report of a case. Journal of Urology, 66, 285.

(Accepted 18 November 1982) 